\title{
www.czasopisma.pan.pl \\ Analysis of the Causes of Cracks in a Thick-Walled Bush Made of Die-Cast Aluminum Bronze
}

\author{
B.P. Pisarek *, D. Kołakowski, T. Pacyniak \\ Department of Materials Engineering and Production Systems, Lodz University of Technology, \\ ul. Stefanowskiego 1/15, 90-924 Łódź, Poland \\ * Corresponding author. E-mail address: boguslaw.pisarek@p.lodz.pl
}

Received 04.05.2016; accepted in revised form 22.06.2016

\begin{abstract}
For the die casting conditions of aluminium bronzes assumed based on the literature data, a thick-walled bush was cast, made of complex aluminium bronze ( $\mathrm{Cu}-\mathrm{Al}-\mathrm{Fe}-\mathrm{Ni}-\mathrm{Cr})$. After the cast was removed from the mould, cracks were observed inside it. In order to identify the stage in the technological production process at which, potentially, the formation of stresses damaging the continuity of the microstructure created in the cast was possible (hot cracking and/or cold cracking), a computer simulation was performed. The article presents the results of the computer simulation of the process of casting the material into the gravity die as well as solidifying and cooling of the cast in the shape of a thick-walled bush. The simulation was performed with the use of the MAGMA5 program and by application of the

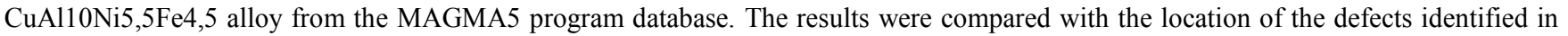
the actual cast. As a result of the simulation of the die-casting process of this bush, potential regions were identified where significant principal stresses accumulate, which can cause local hot and cold cracking. Until now, no research has been made of die-cast aluminium bronzes with a $\mathrm{Cr}$ addition. Correlating the results of the computer simulation validated by the analysis of the actual cast made it possible to clearly determine the critical regions in the cast exposed to cracking and point to the causes of its occurrence. Proposals of changes in the bush die casting process were elaborated, in order to avoid hot tearing and cold cracking. The article discusses the results of preliminary tests being a prologue to the optimization of the die-casting process parameters of complex aluminium bronze thick-walled bushs.
\end{abstract}

Keywords: Application of information technology to the foundry industry, MAGMA5, Die casting, Complex aluminium bronze, Hot tear, Cold crack

\section{Introduction}

Aluminium-iron-nickel bronzes with additions of $\mathrm{Cr}$, Mo and/or $\mathrm{W}$ characterize in high mechanical properties, both in the state as-cast and after thermal treatment [1]. A characteristic property of these alloys is their high abrasive and adhesive wear resistance. This resistance is caused mainly by the fine precipitates of hard phases $\mathrm{K}_{\mathrm{i}}(\mathrm{i}=\{\mathrm{I}, \mathrm{II}, \mathrm{III}, \mathrm{IV}\})$ present in the bronze microstructure and additional intermetallic phases saturated with alloy additions, whose formation proceeds in many stages $[1,2]$. The work [3] discusses the possibility of casting a complex aluminium bronze thick-walled bush by the Lost Foam technology [4]. In order to avoid internal and surface defects of the cast, it was necessary to use high riser heads and a perforated metal chill inside the bush. It was decided to verify the possibility 
of producing such a bush in the die-casting technology, and the verification results are presented in this article. Die-casting of aluminium bronzes is quite difficult due to the cast contraction in the insufficiently flexible steel mould. The work [5] states that, for aluminium bronze, the preliminary heating temperature of the die is in the range of $200-250{ }^{\circ} \mathrm{C}$, and the cast is removed from the mould after cooling to $600{ }^{\circ} \mathrm{C}$. For example, for the $\mathrm{CuAl10Fe} 4 \mathrm{Ni} 4$ aluminium bronze, the casting temperature in the range of $1120-1200{ }^{\circ} \mathrm{C}$ was assumed. For the CuAl10 bronze, in turn, the increase of the die preliminary heating temperature in the range of $150-450{ }^{\circ} \mathrm{C}$ decreases the mechanical properties of the cast, such as: $\mathrm{Rm}$ (about $54 \mathrm{MPa}$ ) - relatively slightly, $\mathrm{Rp}_{0.2}(23-$ $18 \mathrm{MPa})$ and $\mathrm{HB}(140-125)$ to a lager extent than $\mathrm{Rm}$ and a significant increase of A (15-45\%).

A high volume contraction characteristic to aluminium-ironnickel-chromium bronze 3,2-4\% [1,6] under the conditions of intensive cooling of the cast in the die, can be the cause of the formation of hot and cold cracking in the cast. The die-casting parameters, such as: casting temperature $t_{\text {cast }}$, die preliminary heating temperature $t_{\text {die }}$, as well as temperature of removing the cast from the die $t_{\text {out }}$, significantly affect the cast quality (casting defects from the Discontinuity group). They result from the changes in the mechanical properties of the cast, at its solidification and cooling temperatures, which cause a change in the stresses, deformations and dislocations in the cast.

A useful tool in the designing of the casting technology parameters is the MAGMA5 program. It is used to perform computer simulations of the processes of: pouring, solidifying and cooling of the cast and the accompanying changes in the properties of the alloy in the cast. The computer simulations made with its use of a CuAl10Ni3Fe2 (BA1032) bronze cast produced in a sand mould were verified experimentally [7]. In turn, the die casting simulations performed on a CuAl9Fe1Nil bronze cast made it possible to optimize the die construction in order to eliminate contraction cavities and gas porosity in the cast [8].

For many casting technologies, as well as alloy types, intense research is being conducted aiming at identifying the causes of cast hot cracking [9-12], as well as cold cracking [13-15].

The investigations optimizing the parameters of the technological process of die casting of complex aluminium bronze thick-walled casts, from the point of view of minimizing the cast's hot and cold cracking sensitivity, were divided into two stages. At the first stage, examinations of the process of pouring and solidification of the alloy in the die were conducted. A special regard was given to the stress distribution in the cast as well as the deformations, which could be the cause of the formation of potential hot or cold cracks. The planned second stage of the research will concern identifying the effect of the changes in the thick-walled bush die casting process parameters $\left(\mathrm{t}_{\text {cast }}, \mathrm{t}_{\text {die }}, \mathrm{t}_{\text {out }},\right)$ on the change in the hot or cold cracking sensitivity.

With the purpose of a theoretical identification of the stresses occurring in the cast, simulation tests were conducted with the use of the MAGMA5 program. Validation of the simulation results (possibility of the formation and propagation of hot and cold cracking) was performed on a test cast.

\section{Test methodology}

The $\mathrm{CuAl10 \textrm {Fe }} 5 \mathrm{Ni} 5 \mathrm{Cr}$ bronze was melted in an induction furnace, in a silicon carbide crucible. In order to isolate the mirror of liquid metal from the ambient atmosphere, charcoal was used. The latter was introduced onto the surface of the metallic charge before its melting. The die casting parameters are presented in Table 1. The metal die was heated in an electric chamber drier. The coating separating the die material from the liquid alloy was made by the spraying method with the use of a water titanium oxide mixture. Figure 1 shows a section of a test vertical moulding die after liquid alloy was poured into it and the distribution of the thermocouples inside the die. Due to the lack of heat exchange parameters for the $\mathrm{CuAl} 10 \mathrm{Fe} 5 \mathrm{Ni} 5 \mathrm{Cr}$ alloy in the database of the MAGMA5 program, the CuAl10Ni5.5Fe4.5 (according to EN - CC333G) alloy was selected for the simulation of bronze pouring and solidification. The parameters of the die casting process in the simulation were assumed according to the process (Table. 1). For the selected bronze, the coefficient HTCconst $=1500 \mathrm{~W} / \mathrm{m}^{2} \cdot \mathrm{K}$ was assumed. For the die and the core made of a low-alloy steel, the coefficients $\mathrm{HTC}=\mathrm{f}$ (temperature) from the MAGMAdata base were assumed. In the database, for this alloy, the liquidus temperature $\mathrm{TL}=1070{ }^{\circ} \mathrm{C}$ and solidus temperature $\mathrm{TS}=1027^{\circ} \mathrm{C}$ were assumed.

Table 1.

Parameters of the die casting process for alloy $\mathrm{CuAl10Ni5.5 \textrm {Fe } 4 . 5}$

\begin{tabular}{lll}
\hline Parameter & Value & Units \\
\hline Pouring temperature & 1155 & ${ }^{\circ} \mathrm{C}$ \\
\hline Die heating temperature & 175 & ${ }^{\circ} \mathrm{C}$ \\
\hline $\begin{array}{l}\text { Cast temperature on } \\
\text { removal from the die }\end{array}$ & 625 & ${ }^{\circ} \mathrm{C}$ \\
\hline $\begin{array}{l}\text { Die preparation for } \\
\text { pouring }\end{array}$ & 45 & $\mathrm{~s}$ \\
\hline Die casting & 7 & $\mathrm{~S}$ \\
\hline $\begin{array}{l}\text { Time of cast removal } \\
\text { from the die }\end{array}$ & 15 & $\mathrm{~s}$ \\
\hline $\begin{array}{l}\text { Cast treatment after } \\
\text { removal from the die }\end{array}$ & $\mathrm{Cooling}$ in ambient air & \\
\hline $\begin{array}{l}\text { Cast temperature on } \\
\text { simulation end }\end{array}$ & 30 & ${ }^{\circ} \mathrm{C}$ \\
\hline
\end{tabular}

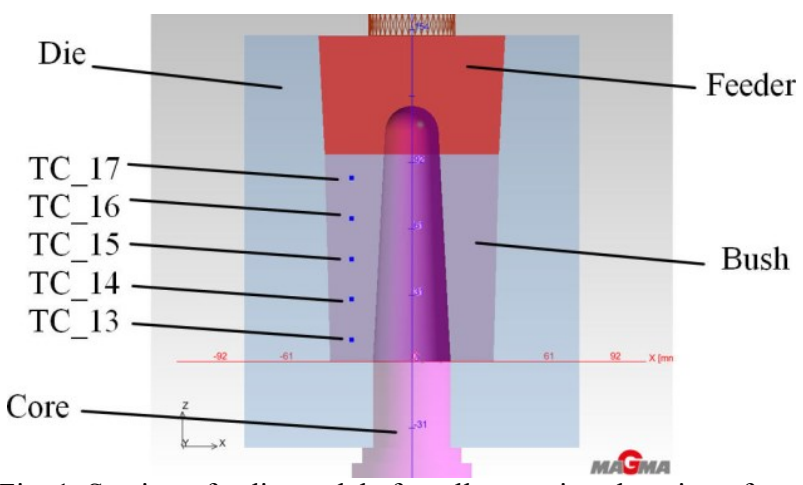

Fig. 1. Section of a die model after alloy casting; location of temperature control points (TC) 


\section{Experiment description}

\subsection{Die casting}

Figure $2(a, b)$ shows the results of the simulation of: filling the die (a) and temperature distribution in the cast after die casting (b). As a result of the assumption that the metal would be poured into the die with the diameter stream of $30 \mathrm{~mm}$ (Circular Inlet $\mathrm{r}=15 \mathrm{~mm}$ ), directly in the die axis, the stream of liquid metal washes the core, and next the internal surface of the die (Fig. 2a). The first stream poured into the die (the oldest) was carried by the hot torus-shaped metal (the youngest) into the riser head. This way of casting generates a parabolic distribution of isotherms on the wall section of the cast cooled by the die surface from the outside, and from the inside - by the surface of the metal core (Fig. 2b).

a)

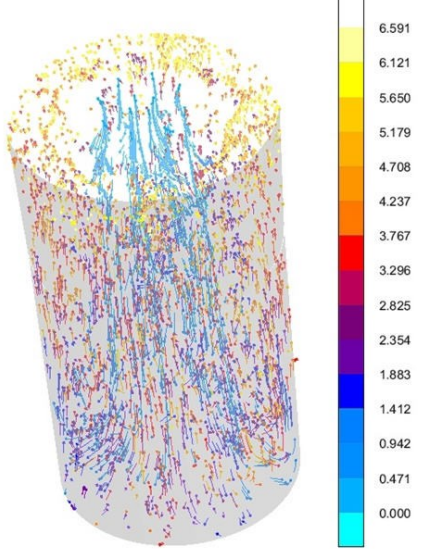

b)
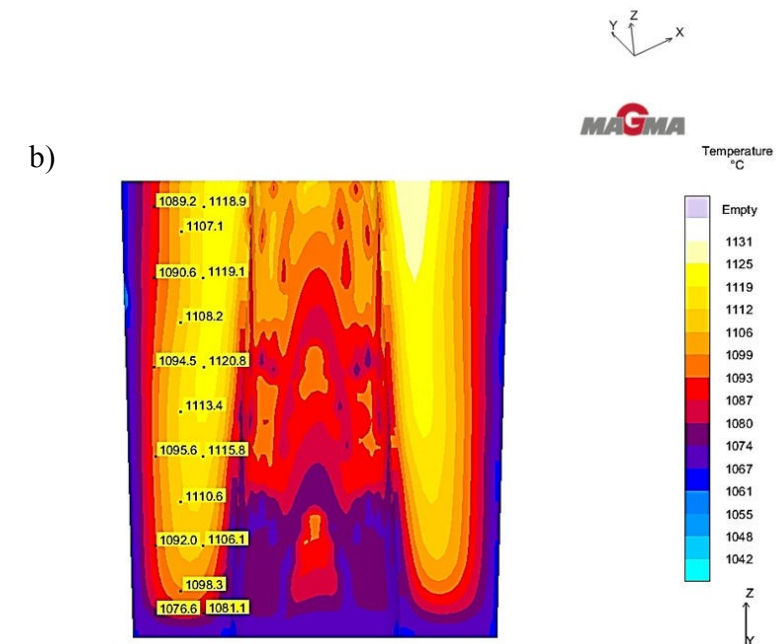

Fig. 2. Markers of filling the mould (a)
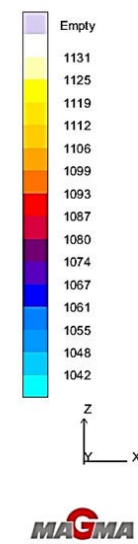

and the temperature distribution in the cast (the bush) after die casting (b)
Due to the unidirectional heat removal by the core (along axis $\mathrm{Z}$ in direction $-\mathrm{Z}$ ), clear densification of isotherms was observed close to its surface. The liquid alloy is cooler on the side of the die and warmer on the side of the core. On the surface of the bush on the side of the core, heterogenic temperature fields were formed.

\subsection{Solidification and cooling of the bush before removal from the die}

Figure $3(a-d)$ shows the simulation results for the movement of the liquid metal front during the solidification and cooling of the bush before the removal from the mould. The isolines of the percentage of the liquid metal $\mathrm{F}_{\mathrm{L}}$ in the die volume move inside the mould similarly to the alloy crystallization front. Their shape depends mostly on the temperature field of the liquid metal after die casting (Fig. 2b). The alloy crystallization begins on the side of the die (Fig. 3a). After some time, necessary to remove the heat of the overheated alloy on the side of the core, the liquid metal becomes overcooled. This makes it possible to form the crystallization front almost parallel to the surface of the core (Fig. $3 b)$. The isolines of the percentage of the liquid metal $F_{L}$ in the volume of the die move inside the mould at different rates. The highest rate is achieved along axis $\mathrm{Z}$, and next - from the surface formed by the bush towards the core, whereas the lowest rate is observed from the surface formed by the core towards the inside of the cast wall section (Fig. 3b-c). Above the spherical surface of the core (in the riser head), the liquid metal takes the longest time to solidify. The alloy in the die volume solidified after $1 \mathrm{~min}$ and $11 \mathrm{~s}$ (Fig. 3d). With the use of the MAGMA5 program, the distribution of the porosity and thermal centres in the bush cast was estimated. Figure $4 \mathrm{a}-\mathrm{c}$ shows the simulation results for: porosity (a), thermal centres (b) and validation based on the actual cast - image of: the section through the riser head of the cast removed from the die (c). From the presented data one can infer a good agreement of the simulation results with the test performed on the actual cast. In the experimental cast, in the upper part of the riser head, contraction porosity was formed (Fig. 4a). As a result of the lack of compensation of the volume contraction of the liquid alloy in the thermal centre (Fig. 4b), a contraction cavity was formed (Fig. 4c).

The simulation results confirm that the designed riser head makes it possible to obtain a bush without porosity and contraction cavity defects.

In the upper part of the bush cast, as a result of the simulation of the Hot Tear criterion, some volumes of the cast were observed to be exposed to this type of cracking. The location of these areas is shown in Figure 5. For the selected point (micro-volume of the cast described by a differential network), the changes in the characteristic properties simulated in the MAGMA5 program were analyzed: Hot Tear, initial strength $\mathrm{Rm}$ and maximal principal stress, and they are shown in Figure 6. From the presented simulation results (Fig. 5 and 6) it should be inferred that, in the selected micro-area, it is very probable to observe Hot Tear.

With the use of the MAGMAstress module of the MAGMA5 program, designed to determine stresses in the cast, the hot cracking criterion was calculated. Assessment was made of the deformation rates during alloy solidification until the moment when it was no longer possible to power the local thermal centres 
by the liquid alloy through the network of crystallized phase $\beta$ dendrites.

a)
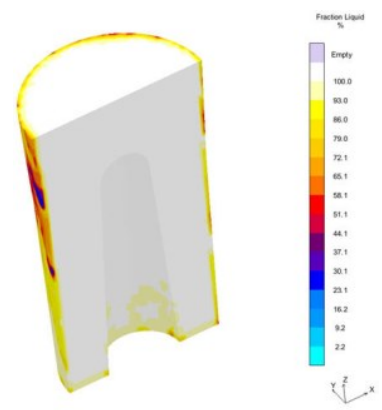

b)
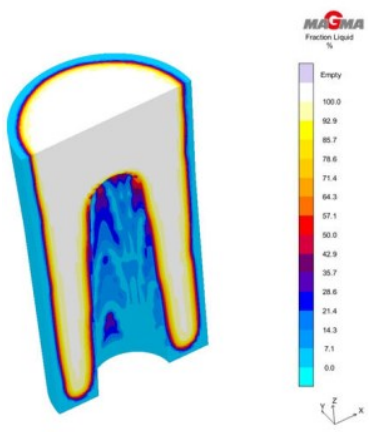

c)
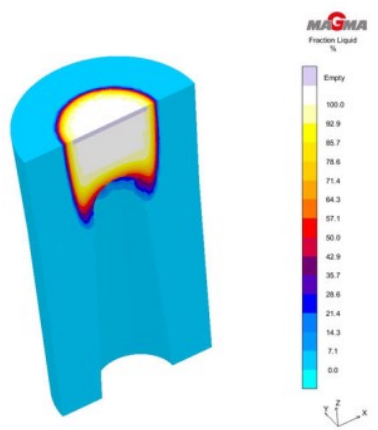

d)

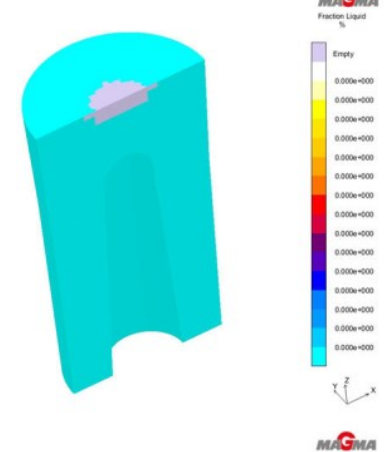

Fig. 3. Change in the participation of the liquid alloy $F_{L}$ in the cast, in the function of time $\tau$ :

a) $\tau=7.035 \mathrm{~s} \mathrm{~F}_{\mathrm{L}}=99.91 \%$, b) $\tau=15.136 \mathrm{~s} \mathrm{~F}_{\mathrm{L}}=67.71 \%$, c) $\tau=44.031 \mathrm{~s} \mathrm{~F}_{\mathrm{L}}=7.98 \%$, d) $\tau=1 \min 11 \mathrm{~s} \mathrm{~F}_{\mathrm{L}}=0 \%$,

From the presented data (Fig. 6) concerning the changes of the hot cracking criterion as well as the initial strength $\mathrm{Rm}$ and the maximal principal stresses it can be inferred that the critical areas in which hot cracking may occur are localized in the upper part of the cast on the side of the core. These areas are formed between 34 and $44 \mathrm{~s}$ from the moment of filling the die with the liquid bronze, and the local values of the hot cracking criterion reach $\geq 0.7$.

a)

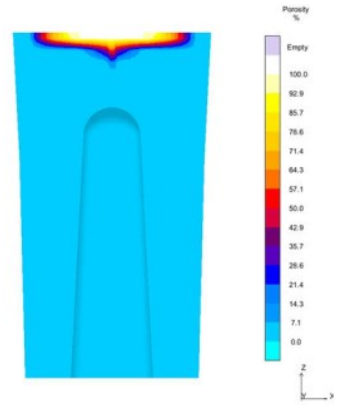

b)

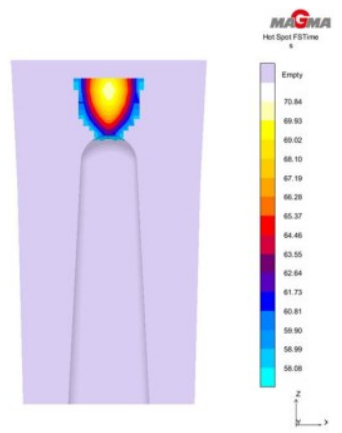

c)

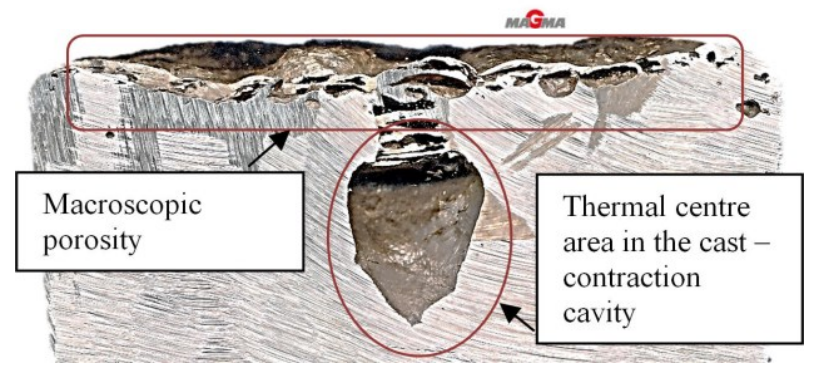

Fig. 4. Results of: simulation of the location in the cast porosity (a), thermal centres (b) and validation - image of: the section through the riser head of the cast removed from the die (c)

In this time range, for the selected control point in the temperature range of $1042-1037{ }^{\circ} \mathrm{C}\left(\mathrm{TS}=1027^{\circ} \mathrm{C}\right)$, we can observe a clear increase of the principal compressive stresses. The risk of hot cracking grows as a result of high contraction stress, which is characteristic in the casting of complex aluminium bronzes, and when the casting alloy is limited by the rigid cores or the mould material (die casting). The mechanical properties ( $\mathrm{Rm}$ at the given temperature, principal stresses) of the cast structure in the temperature range slightly above the solidus temperature are especially important. The dendrite network exhibits the ability for load transfer, similarly to solids. However, the smallest deformations can form cracks, as the network is very brittle.

In the macroscopic tests of the cast, there were no observations of hot cracks whose edges would reach the surface 
of the bush. Also, in the selected section of the bush, no such cracks were revealed. However, we cannot be $100 \%$ certain that no cracks occurred beneath the cast surface.

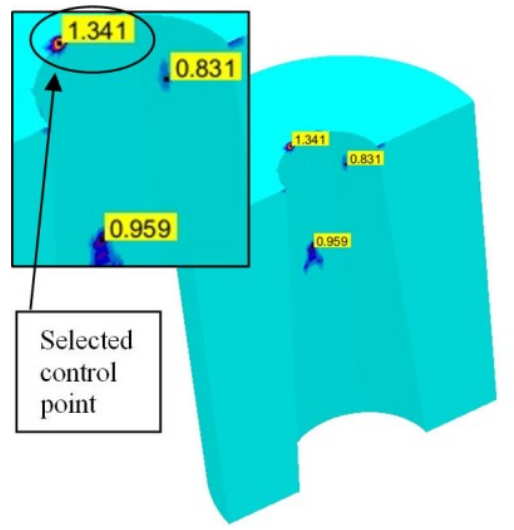

Fig. 5. Criterion of Hot Tear sensitivity

- Hot Tear $\tau=1 \min 11.0 \mathrm{~s}$

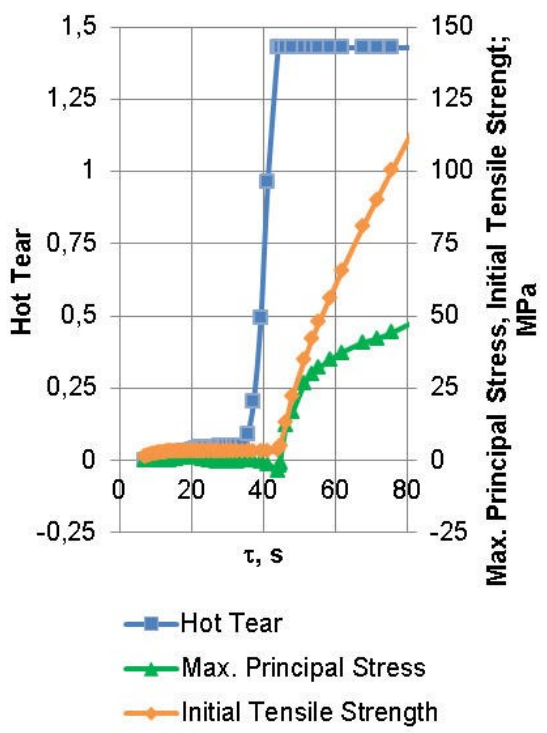

Fig. 6. Change in the function of time: criterion of Hot Tear, initial strength $\mathrm{Rm}$, maximal principal stresses

In the lower part of the bush cast, based on the simulation of the cold cracking sensitivity criterion, certain volumes of the cast exposed to the risk of such type of cracking were also observed. The location of these areas is presented in Figure 7. For the selected point (cast micro-volume described by the differential network), the changes in the characteristic properties simulated in the MAGMA5 program were analyzed: cold cracking sensitivity criterion, initial yield point $\mathrm{Rp}$, initial strength $\mathrm{Rm}$, Von Mises (reduced) stresses, maximal principal stresses, effective principal stresses (Figure 8).

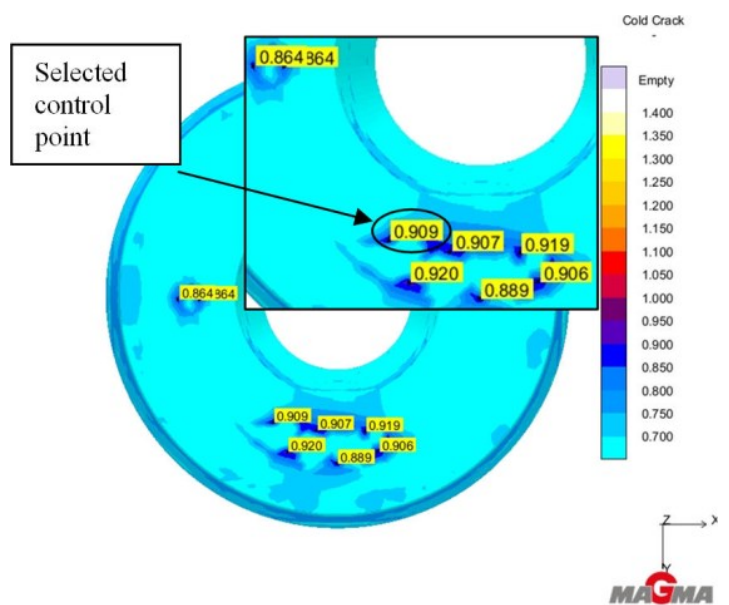

Fig. 7. Criterion of Cold Crack sensitivity - Cold Crack $\tau=1 \mathrm{~min} 11.0 \mathrm{~s}$

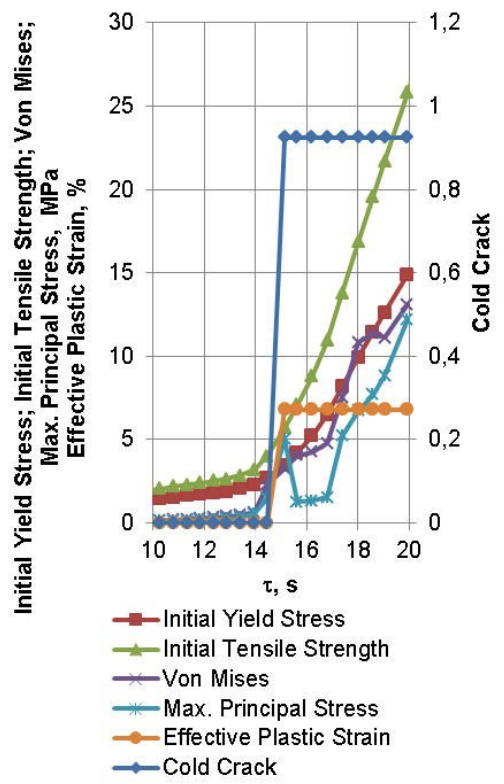

Fig. 8. Change in the function of time of: criterion of Cold Crack sensitivity, initial yield point $\mathrm{Rp}$, initial strength $\mathrm{Rm}$, maximal principal stresses, effective plastic deformation

From the presented simulation results (Fig. 7 and 8), it should be inferred that, in the selected micro-area, it is very probable to observe cold cracking. In the macroscopic tests of the cast, a cold crack was identified in the lower part of the bush.

Figure 9 shows an image of the bush section from this area with a visible crack in the wall of the bush formed by the core. Already after $15 \mathrm{~s}$, after die casting, a significant increase of principal stresses was observed in the control point, with a relatively low initial tensile strength. 


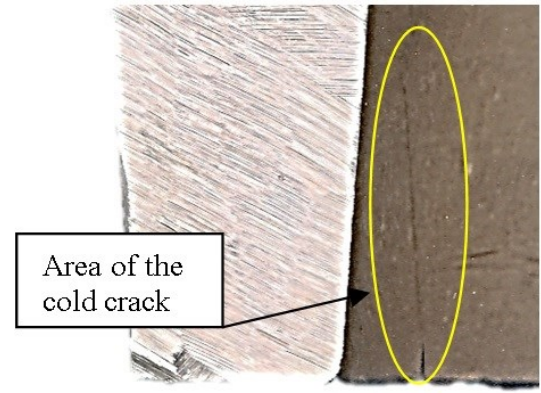

Fig. 9. Image of the section through the lower part of the bush with a visible cold crack on the surface of the cast formed by the core

During the solidification and cooling of the cast, in the solidified regions, we observe accumulation of stresses. The latter can exceed the tensile strength and thus lead to cold cracking in the cast. In the case when the cracks occurs below the solidus temperature, they are identified as cold cracks. In the assessment of the cold cracking sensitivity in the MAGMAstress module, the calculated Von Mises stresses were used together with the maximal principal stresses, and they were compared with the tensile strength dependent on temperature. The risk of cracking increases in the range from 0.8 to 1 . The lowest value 0.8 , depends on the actual casing process, alloy type and ambient conditions in the foundry. Probably, the main reason for the increase in the cold cracking sensitivity in the examined bush is the core being removed too late. The removal of the core required quite a high strength, which probably introduced additional stresses into the cast and caused propagation of cold cracks.

\section{Conclusions}

From the performed simulation of the casting process, solidification and cooling of the thick-walled bush cast, one can draw the following conclusions:

- $\quad$ in order to avoid the presence of critical areas exposed to hot cracking in the bush, one should try to shorten the time of bronze solidification in these areas or reduce the rigidness of the core material,

- $\quad$ in order to avoid the presence of areas exposed to cold cracking in the bush, one should remove the core from the cast earlier or change the manner of filling the die,

- $\quad$ from the point of view of minimizing the cast's hot and cold cracking sensitivity, one should perform examinations optimizing the technological process of die casting of complex aluminum bronze thick-walled casts.

\section{References}

[1] Pisarek, B. (2013). Aluminium Bronze Containing Cr, Mo and/or $W$ with High Resistance to Wear. Łódź: Scientific Bulletin of the Lodz University of Technology No. 1141, Wydawnictwo Politechniki Łódzkiej. (in Polish).
[2] Pisarek, B.P. (2013). Model of Cu-Al-Fe-Ni Bronze Crystallization. Archives of Foundry Engineering. 13(3), 7279.

[3] Just, P. \& Pisarek, B.P. (2014). Feeding and Cooling and Time of Thermal Treatment of a Massive Bush Made of the Complex Aluminum Bronze Cast by the Lost Foam. Archives of Foundry Engineering. 14(4), 39-44.

[4] Pacyniak, T. (2013). Method of full-mold. Selected aspects. Łódź, Wydawnictwo Politechniki Łódzkiej. (in Polish).

[5] Górny, Z. \& Lech Z. (1975). Die-casting non-ferrous alloys. Warszawa: WNT. (in Polish).

[6] Pisarek, B. (2011). Simulation of volumetric shrinkage Sv and surface shrinkage Svp. Pietrowski S. (Eds.), Wysokojakościowe Technologie Odlewnicze, Materiaty $i$ Odlewy. (167-208), Katowice - Gliwice, PAN.

[7] Górny, Z., Kluska-Nawarecka, S. \& Połcik, H. (2003). Simulation of solidification of BA1032 aluminum bronze with experimental verification. Archives of Foundry. 3(9), 140-147. (in Polish).

[8] Fajkiel, A., Dudek, P., Walczak, W. \& Zawadzki P. (2007). Improvement of quality of a gravity die casting made from aluminum bronze be application of numerical simulation. Archives of Foundry Engineering. 7(2), 11-14.

[9] Chojecki, A., Burbiełko, A. \& Telejko, I. (2005). Formation of Hot Tears in High Strength Al-Cu Alloys. Archives of Foundry. 5(15), 53-59.

[10] Pokorny, M., Monroe, C., Beckermann, C., Bichler, L. \& Ravindran, C. (2008). Prediction of Hot Tear Formation in a Magnesium Alloy Permanent Mold Casting. International Journal of Metalcasting. Fall 08, 41-53.

[11] Norouzi, S., Shams, A., Farhangi, H. \& Darvish, A. (2009). The temperature range in the simulation of residual stress and hot tearing during investment casting. International Scholarly and Scientific Research \& Innovation. 3(10), 558564.

[12] D'Elia, F., Ravindran, C., Sediako, D., Kainer, K.U. \& Hort, N. (2014) Hot tearing mechanisms of B206 aluminumcopper alloy. Materials and Design. 64, 44-55.

[13] Dong, S., Iwata, Y., Sugiyama, Y. \& Iwahori, H. (2010). Cold Crack Criterion for ADC12 Aluminum Alloy Die Casting. Materials Transactions. 51(2), 371-376.

[14] Lalpoor, M., Eskin, D.G. \& Katgerman, L. (2010). Cold Cracking Development in AA7050 Direct Chill-Cast Billets under Various Casting Conditions. Metallurgical And Materials Transactions. A 41a, 2425-2434.

[15] Lalpoor, M., Eskin, D.G., Ruvalcaba, D., Fjǽr, H.G., Ten Cate, A., Ontijt, N. \& Katgerman, L. (2011). Cold cracking in DC-cast high strength aluminum alloy ingots: An intrinsic problem intensified by casting process parameters. Materials Science and Engineering. A 528, 2831-2842 